\title{
Difference Hirshfeld fingerprint plots: A tool for studying polymorphs
}

\author{
Damien J. Carter, ${ }^{a}$ Paolo Raiteri, ${ }^{a}$ Keith R. Barnard,${ }^{b}$ Rhian Gielink, ${ }^{c}$ Mauro Mocerino,,${ }^{c}$ Brian W. \\ Skelton, ${ }^{d}$ Jamila G. Vaughan ${ }^{c}$, Mark I. Ogden, ${ }^{c, d}$ and Andrew L. Rohl ${ }^{a}$ \\ Received (in $X X X, X X X)$ Xth $X X X X X X X X X 20 X X$, Accepted Xth $X X X X X X X X X 20 X X$ \\ DOI: 10.1039/b000000x
}

A new tool has been developed to help elucidate the differences in packing between different polymorphs, especially when the differences of interest are small. The technique builds upon the Hirshfeld fingerprint plot pioneered by Spackman and co-workers by subtracting the value at every point in a fingerprint plot from the value at every point in another. This is found to reveal differences that are not readily apparent to the eye. By summing the absolute values of these differences, a quantitative measure of the difference between 10 two fingerprint plots can be obtained. The technique was applied to $\mathrm{Ni}$ and $\mathrm{Cu}$ trans-bis(2-hydroxy-5-methylphenonethanoneoximato) complexes determined at two temperatures, with the Ni complex displaying temperature-dependent polymorphism. Difference Hirshfeld fingerprint plots were also generated for calculated structures from DFT simulations that were performed on the experimental structures. These demonstrated that the simulations reproduced the fine detail of the packing.

\section{${ }_{15}$ Introduction}

Hirshfeld surfaces have become an invaluable tool for crystallographers and crystal engineers alike. Hirshfeld surfaces enclose molecules within crystals and are defined as the region where the contribution from the electron density within a 20 molecule exceeds that from all other molecules in the crystal ${ }^{1}$. For each point on the Hirshfeld surface, the distance to the nearest atom within the molecule, $d_{i}$, can be calculated. Likewise the distance to the nearest atom on the neighbouring molecule, $d_{e}$, can also be determined. Plotting these as a 2-D histogram ${ }_{25}$ produces the fingerprint plot $^{2}$.

McKinnon and coworkers demonstrated that fingerprint plots are a useful tool to study polymorphism by visually comparing the plots of different polymorphs and noting the differences ${ }^{3}$. This 30 type of visual comparison has been used in a number of studies since in systems ranging from simple molecules such as cis-1,4cyclohexanediol ${ }^{4}$, pyrazinamide ${ }^{5}$ and rubrene ${ }^{6}$ to a variety of pharmaceutically relevant compounds ${ }^{7}$ to ligands ${ }^{8}$. We have previously used fingerprint plots to elucidate the differences 35 between the five polymorphs of 1,8-dihydroxyanthraquinone ${ }^{9}$, but in addition we also used them to compare experimental and calculated structures of each polymorph. In a similar vein, Schatschneider and Liang used fingerprint plots to monitor structural changes as they simulated compression of crystalline 40 indole ${ }^{10}$. Parkin and coworkers ${ }^{11}$ have used cluster analysis and multivariate statistics to calculate similarity indices between different structures and this work has been extended by Collins and coworkers ${ }^{12}$. The latter also examined the effects of temperature on the fingerprint plots of anthracene and noted "The

${ }_{45}$ plots are very similar and represent a challenge to any data mining technique". Latfosińska and coworkers ${ }^{13}$ also found small differences between the fingerprint plots of the polymorphs of 3,3'-diindolylmethane determined at several temperatures and defined several measures to quantify the differences.

50

When the plots are very similar, determining the differences can be a challenge for humans as well as machines. We have been thinking about this challenge for some time but the discovery of temperature-dependent polymorphism in some phenolic oximes ${ }_{55}$ pushed our ideas forward.

Phenolic oximes are important reagents in the solvent extraction of copper. The extractants are typically derived from salicylaldehydes or o-ketophenols, and form square planar ${ }_{60}$ complexes stabilized by intramolecular hydrogen bonds (Scheme 1) ${ }^{14}$. "Folded" octahedral nickel complexes of these ligands have been reported when isolated in the presence of chelating diamines ${ }^{14}$. The diamines also impact on the solvent extraction behaviour, forming a synergistic system with enhanced nickel extraction. We ${ }_{65}$ have previously reported synergistic solvent extraction systems based on aliphatic $\alpha$-hydroxyoximes and carboxylate ligands ${ }^{15-17}$. While attempting to extend this work to phenolic oxime ligands, we crystallised the simple square planar nickel and copper complexes, and observed temperature-dependent polymorphism 70 in the nickel complex.

Here we report the experimental determination of the low temperature $\mathrm{Ni}$ oxime structure and the low and high temperature $\mathrm{Cu}$ oxime structures using single crystal $\mathrm{X}$-ray diffraction with 75 accompanying DFT calculations investigating the stability of $\mathrm{Cu}$ and $\mathrm{Ni}$ substituted in the low and high temperature $\mathrm{Ni}$ and $\mathrm{Cu}$ oximes structures. These yielded a significant number of very similar Hirshfeld fingerprint plots, which prompted a detailed examination of these structures and development of an approach 80 to probe subtle changes in crystal packing. 


\section{Methodology}

${ }_{5}$ Ligand synthesis

2-Hydroxy-5-methylacetophenoneoxime HL was synthesised following literature methods ${ }^{18}$. A mixture of 2-hydroxy-5methylacetophenone (19.69 g, $0.131 \mathrm{~mol})$ was combined with hydroxylamine hydrochloride (25.15 g, $0.36 \mathrm{~mol})$, ethanol (220 $10 \mathrm{~mL}$ ) and pyridine $(21 \mathrm{~mL})$ and the reaction mixture gently heated at reflux for 2 hours. The ethanol then was removed under reduced pressure and the residue dissolved in ether. The ether solution was washed with $1 \mathrm{M} \mathrm{HCl}$ to remove the pyridine. The organic layer was then evaporated leaving white solid oxime HL 15 which was recrystallised from an ethanol /water mixture to provide the pure oxime as white needles $(18.5 \mathrm{~g}, 85 \%)$, m.p. 140-142 ${ }^{\circ} \mathrm{C} .{ }^{1} \mathrm{H}$ NMR $\left(\mathrm{CDCl}_{3}\right)$ : d 2.20, 2.25 (2s, 6H, 2CH3), 6.75 $(1 \mathrm{H}, \mathrm{ArH}), 7.12(2 \mathrm{H}, \mathrm{ArH}), 7.84(1 \mathrm{H}, \mathrm{ArOH}), 10.95$ (=N-OH); IR (KBr, cm-1): $3330 \quad(=\mathrm{N}-\mathrm{OH}$ stretch $), 2900-2800 \quad(\mathrm{C}-\mathrm{H}$ 20 stretching), 1635 (C=N stretching), 1503 (Aromatic) and $956(\mathrm{~N}$ $\mathrm{O}$ stretching); GC-MS (m/z ion), $165\left(\mathrm{M}^{+}\right), 118\left(\mathrm{C}_{7} \mathrm{H}_{4} \mathrm{NO}^{+}\right)$and $77\left(\mathrm{C}_{6} \mathrm{H}_{5}^{+}\right)$.

\section{Metal complexation}

${ }_{25}$ In a typical procedure, the metal nitrate hydrate $(0.11 \mathrm{mmol})$ was dissolved in ethanol or ethyl acetate $(10 \mathrm{~mL})$, and combined with a solution of $\mathrm{HL}(0.24 \mathrm{mmol})$, synergist $(0.24 \mathrm{mmol})$ and $\mathrm{NEt}_{3}$ $(0.48 \mathrm{mmol})$ in ethanol or ethyl acetate $(10 \mathrm{~mL})$. The synergists used included dibutylphosphoric acid, phenylphosphinic acid, ${ }_{30}$ phenylphosphonic acid, bis(3,5,5-trimethylpentyl)phosphinic acid, and mono 2-ethylhexyl phosphoric acid (MEHPA). No phosphorus containing products were isolated, and aside from one example where the product was recrystallized from hot DMSO (see SI), only the $\mathrm{ML}_{2}$ products crystallised.

\section{Crystallography}

Crystallographic data for the structures were collected at 100(2) $\mathrm{K}$ on an Oxford Diffraction Xcalibur diffractometer fitted with $\mathrm{Mo} \mathrm{K} \alpha$ radiation. Following analytical absorption corrections and 40 solution by direct methods, the structure was refined against $F^{2}$ with full-matrix least-squares using the program SHELXL-97 ${ }^{19}$. All hydrogen atoms were added at calculated positions and refined by use of a riding model with isotropic displacement parameters based on those of the parent atoms. Anisotropic 45 displacement parameters were employed for all the non-hydrogen atoms.

\section{Crystal data and refinement details}

$\mathrm{NiL}_{2} \cdot \mathrm{T}=100 \mathrm{~K}$. Empirical formula $\mathrm{C}_{18} \mathrm{H}_{20} \mathrm{~N}_{2} \mathrm{NiO}_{4}$; formula 50 weight 387.07, triclinic, space group $P \overline{1} ; a=6.4680(13), b=$ 7.7544(16), $c=8.6026(17) \AA, \alpha=97.267(17), \beta=109.253(18), \gamma$ $=96.531(17)^{\circ}, V=398.46(14) \AA^{3}, Z=1, D_{\mathrm{c}}=1.613 \mathrm{Mg} / \mathrm{m}^{3}, \mu=$ $1.244 \mathrm{~mm}^{-1}$, crystal size $=0.39 \times 0.14 \times 0.10 \mathrm{~mm}^{3} ; \theta_{\min , \max }, 3.36$, $37.22^{\circ}$, reflections collected $=7581$; independent reflections ${ }_{55}=3960\left[R_{\text {int }}=0.0295\right]$, data/restraints/parameters 3960/0/118, goodness-of-fit on $F^{2}=0.941$; final $\mathrm{R}$ indices $[I>2 \sigma(I)] R_{1}=$ $0.0401, w R_{2}=0.0809 ; \mathrm{R}$ indices (all data) $R_{1}=0.0572, w R_{2}=$ 0.0841 . Largest diff. peak and hole $=0.890$ and -0.761 e. $\AA^{-3}$. $\mathrm{CCDC}=1519180$.

60

$\mathrm{CuL}_{2} \cdot \mathrm{T}=100 \mathrm{~K}$. Empirical formula $\mathrm{C}_{18} \mathrm{H}_{20} \mathrm{CuN}_{2} \mathrm{O}_{4}$; formula weight 391.90, triclinic, space group $P \overline{1} ; a=6.2433(4), b=$ 8.0884(6), $c=8.6219(7) \AA, \alpha=71.541(7), \beta=79.573(6), \gamma=$ $85.986(6)^{\circ}, V=406.13(5) \AA^{3}, Z=1, D_{\mathrm{c}}=1.602 \mathrm{Mg} / \mathrm{m}^{3}, \mu=$ ${ }_{65} 1.371 \mathrm{~mm}^{-1}$, crystal size $0.31 \times 0.08 \times 0.06 \mathrm{~mm}^{3} ; \theta_{\text {min,max }}$, $3.05,37.20^{\circ}$, reflections collected $=7403$; independent reflections $=4073\left[R_{\text {int }}=0.0280\right]$, data $/$ restraints $/$ parameters $4073 / 0 / 118$, goodness-of-fit on $F^{2}=1.067$; final $\mathrm{R}$ indices $[I>2 \sigma(I)] R_{1}=$ $0.0412, w R_{2}=0.0935 ; \mathrm{R}$ indices (all data) $R_{1}=0.0475, w R_{2}=$ 700.0985 . Largest diff. peak and hole $=0.834$ and -0.591 e. $\AA^{-3}$. $\mathrm{CCDC}=1519181$.

$\mathrm{CuL}_{2} . \mathrm{T}=150 \mathrm{~K}$. Empirical formula $\mathrm{C}_{18} \mathrm{H}_{20} \mathrm{CuN}_{2} \mathrm{O}_{4}$; formula 75 weight 391.90 , triclinic, space group $P \overline{1} ; a=6.2388(2), b=$ 8.1434(2), $c=8.6344(3) \AA, \alpha=71.421(3), \beta=79.600(3), \gamma=$ 85.781(2) ${ }^{\circ}, V=408.92(2) \AA^{3}, Z=1, D_{\mathrm{c}}=1.591 \mathrm{Mg} / \mathrm{m}^{3}, \mu=$ $1.362 \mathrm{~mm}^{-1}$, crystal size $0.27 \times 0.09 \times 0.07 \mathrm{~mm}^{3} ; \theta_{\min , \max }, 3.03$, $40.86^{\circ}$, reflections collected $=19572$; independent reflections ${ }_{80}=5231\left[R_{\text {int }}=0.0294\right]$, data $/$ restraints $/$ parameters $5231 / 0 / 118$, goodness-of-fit on $F^{2}=1.065$; final $\mathrm{R}$ indices $[I>2 \sigma(I)] R_{1}=$ $0.0324, w R_{2}=0.0841 ; \mathrm{R}$ indices (all data) $R_{1}=0.0363, w R_{2}=$ 0.0865 . Largest diff. peak and hole $=0.630$ and -0.437 e. $\AA^{-3}$. $\mathrm{CCDC}=1519182$.

\section{Computations}

DFT calculations were performed using the Quantum ESPRESSO ${ }^{20}$ code. The projector-augmented wave (PAW) method ${ }^{21}$ with pseudopotentials adapted from the atompaw ${ }_{90}$ library ${ }^{22}$ was used. The planewave basis set had a kinetic energy cutoff of 80 Ry and the exchange-hole dipole moment (XDM) method ${ }^{23,24}$ was used, in particular B86b-XDM, which combines B86b ${ }^{25}$ exchange with PBE ${ }^{26}$ correlation, with the XDM parameters $\mathrm{A} 1=0.337$ and $\mathrm{A} 2=2.488$. Both $\mathrm{Cu}$ and $\mathrm{Ni}$ atoms 95 substituted in the low and high temperature $\mathrm{Ni}$ and $\mathrm{Cu}$ oxime structures were examined. Calculations include spin polarisation and both atomic coordinates and lattice parameters were optimised using the BFGS quasi-newton method with a maximum tolerance of $0.001 \mathrm{Ry} / \mathrm{Bohr}$.

100

Hirshfeld surfaces were generated using the CrystalExplorer code 27 at very high resolution. By unchecking the Remove working files option with the Expert plane of the Preferences dialog box, the raw surface data is written to a file with a cxs extension. ${ }_{105}$ Within this file are the vertices of the triangles comprising the Hirshfeld surface as well as the corresponding $d_{e}$ and $d_{i}$ values of each vertex. A Fortran 90 code, fingerprint, has been developed that reads in this information, calculates the area of each triangle and adds it to the grid point corresponding to its average $d_{e}$ and $110 \mathrm{~d}_{\mathrm{i}}$. The code then outputs the grid of $\mathrm{d}_{\mathrm{e}}$ and $\mathrm{d}_{\mathrm{i}}$ values along with the accumulated area normalised such that the total area sums to 
$100 \%$. The fingerprint plot can then be viewed using the freely distributed Gnuplot. A script plot_finger has been written that uses a scale and colour scheme that exactly reproduces the fingerprint plots generated by CrystalExplorer. A C program, 5 diff_finger, has been developed that takes two files generated by the fingerprint codes and subtracts them. Finally, the script plot_diff_finger uses Gnuplot to plot the output of diff_finger using a palette that goes from blue (negative) to white (zero) to red (positive). All of these programs and scripts are available 10 online ${ }^{28}$.

\section{Results \& Discussion}

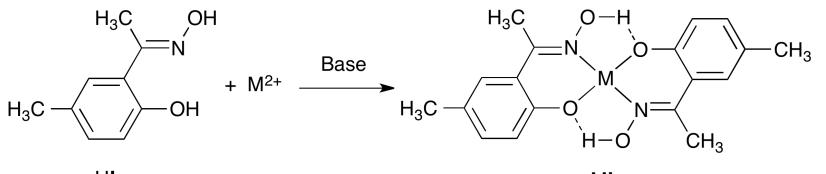
$\mathrm{HL}$

$\mathrm{ML}_{2}$

Scheme 1. General reaction scheme for the formation of a typical $\mathbf{M L}_{2}$ complex with 2-hydroxy-5-methylacetophenoneoxime, HL.

15 Following on from our work with synergistic solvent extraction systems based on aliphatic $\alpha$-hydroxyoximes ${ }^{15-17}$, copper and nickel complexes of ketoxime HL were crystallised in the presence of a range of potential co-extractants. The only system that gave a modified coordination sphere resulted from the 20 reaction of HL with nickel nitrate where dimethylsulfoxide molecules were found in the axial positions. In addition, however, the ligand was nitrated in the ortho position under the reaction conditions (see SI) ${ }^{29}$. In the course of this work, the $\mathrm{CuL}_{2}$, and $\mathrm{NiL}_{2}$ complexes were isolated and structurally characterised. A ${ }_{25}$ room temperature structure of $\mathrm{NiL}_{2}$ has been reported previously ${ }^{30}$, but here it was found that the system undergoes a reversible structural transition at $\sim 150 \mathrm{~K}$ to give a polymorph with a substantially changed unit cell (Table 1). The difference in the structures of the two polymorphs lies in the degree of rotation of 30 the molecule. The angle between the $\mathrm{Ni} \ldots \mathrm{Ni}(\mathrm{x}, \mathrm{y}, 1+\mathrm{z})$ vector and the plane of the molecule increases from $3.4^{\circ}$ at room temperature to $13.2^{\circ}$ at $100 \mathrm{~K}$. This is shown in the two cell projections down the $c$ axes, Fig. 1a of the room temperature structure and Fig. $1 \mathrm{~b}$ for the structure at $\mathrm{T}=100 \mathrm{~K}$. In contrast, 35 the $\mathrm{CuL}_{2}$ structure was found to be isomorphous with the room temperature $\mathrm{Ni}$ structure at both $100 \mathrm{~K}$ and $150 \mathrm{~K}$. In both polymorphs, face-to-face interactions between the planar molecules dominate. The observation that the nickel $\mathbf{L}$ complex has a structural transition as temperature changes, and the 40 isomorphous copper complex does not, led us to undertake a theoretical study to explain why this difference occurs.

Table 1. Experimental lattice parameters for $\mathrm{ML}_{2}$ complexes.

\begin{tabular}{|c|c|c|c|c|c|c|}
\hline $\mathrm{M}$ & $\mathrm{a}(\AA)$ & $\mathrm{b}(\AA)$ & $\mathrm{c}(\AA)$ & $\alpha\left(^{\circ}\right)$ & $\beta\left(^{\circ}\right)$ & $\gamma\left(^{\circ}\right)$ \\
\hline $\mathrm{Cu} @$ & $6.2433(4)$ & $8.0884(6)$ & $8.6219(7)$ & $71.541(7)$ & $79.573(6)$ & $85.986(6)$ \\
$100 \mathrm{~K}$ & & & & & & \\
\hline $\mathrm{Cu} @$ & $6.2388(2)$ & $8.1434(2)$ & $8.6344(3)$ & $71.421(3)$ & $79.600(3)$ & $85.781(2)$ \\
$150 \mathrm{~K}$ & & & & & & \\
\hline $\mathrm{Ni} @$ & $6.4680(13)$ & $7.7544(16)$ & $8.6026(17)$ & $97.267(17)$ & $109.253(18)$ & $96.531(17)$ \\
$100 \mathrm{~K}$ & \multicolumn{7}{|c|}{} & & & & \\
\hline $\mathrm{Ni} @$ & $6.296(5)$ & $8.204(7)$ & $8.653(8)$ & $71.92(6)$ & $80.61(7)$ & $83.84(6)$ \\
$\mathrm{RT}^{*}$ & & & & & & \\
\hline
\end{tabular}

* The experimental $\mathrm{NiL}_{2} \mathrm{RT}$ structure has been reported by Voutsas, et al. ${ }^{30}$ (a)

(b)
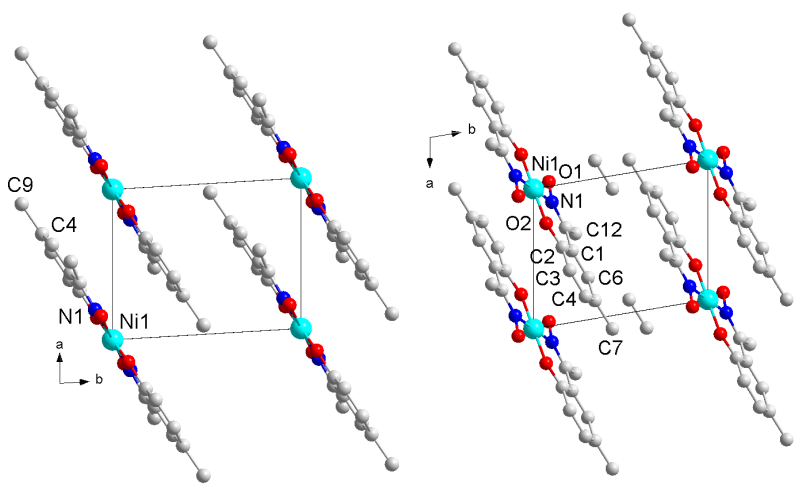

Figure 1. Unit cell contents of the (a) room temperature determination

${ }^{30}$ and (b) low temperature structure of $\mathrm{Ni}(\mathbf{L})_{2}$ projected down the ${ }_{50}$ crystallographic $c$ axis. Hydrogen atoms have been omitted for clarity.

In Table 2, the calculated lattice parameters from DFT calculations of $\mathrm{Ni}$ and $\mathrm{Cu}$ atoms starting from the four experimentally determined $\mathbf{L}$ oxime structures are reported. Where directly comparable to each experimental structure, the ${ }_{55}$ percentage difference to the corresponding experimental lattice parameter has been included.

60 Table 2. Calculated lattice parameters of the high and low temperature $\mathrm{Cu}_{2}$ and $\mathrm{Ni}_{2}$ complexes.

\begin{tabular}{|c|c|c|c|c|c|c|}
\hline Structure & $\mathrm{a}(\AA)$ & $\mathrm{b}(\AA)$ & c $(\AA)$ & $\alpha\left(^{\circ}\right)$ & $\beta\left(^{\circ}\right)$ & $\gamma\left({ }^{\circ}\right)$ \\
\hline $\begin{array}{l}\mathrm{CuL}_{2} @ 100 \mathrm{~K} \\
\mathrm{Cu} \\
\mathrm{Ni}\end{array}$ & $\begin{array}{c}6.24 \\
(-0.01) \\
6.20 \\
\end{array}$ & $\begin{array}{c}8.05 \\
(-0.47) \\
8.01 \\
\end{array}$ & $\begin{array}{c}8.61 \\
(-0.11) \\
8.58\end{array}$ & $\begin{array}{c}70.85 \\
(-0.96) \\
71.97\end{array}$ & $\begin{array}{c}78.53 \\
(-1.31) \\
79.71\end{array}$ & $\begin{array}{l}86.35 \\
(0.43) \\
85.62\end{array}$ \\
\hline $\begin{array}{l}\mathrm{CuL}_{2} @ 150 \mathrm{~K} \\
\mathrm{Cu} \\
\mathrm{Ni}\end{array}$ & $\begin{array}{c}6.24 \\
(0.07) \\
6.21 \\
\end{array}$ & $\begin{array}{c}8.05 \\
(-1.15) \\
8.00 \\
\end{array}$ & $\begin{array}{c}8.61 \\
(-0.23) \\
8.58 \\
\end{array}$ & $\begin{array}{c}70.85 \\
(-0.79) \\
71.99 \\
\end{array}$ & $\begin{array}{c}78.52 \\
(-1.36) \\
79.75 \\
\end{array}$ & $\begin{array}{l}86.35 \\
(0.67) \\
85.61 \\
\end{array}$ \\
\hline $\begin{array}{l}\mathrm{NiL}_{2} @ 100 \mathrm{~K} \\
\mathrm{Ni} \\
\mathrm{Cu}\end{array}$ & $\begin{array}{c}6.40 \\
(-1.13) \\
6.40 \\
\end{array}$ & $\begin{array}{c}7.76 \\
(0.03) \\
7.80 \\
\end{array}$ & $\begin{array}{c}8.61 \\
(0.11) \\
8.57 \\
\end{array}$ & $\begin{array}{c}98.64 \\
(1.41) \\
100.07\end{array}$ & $\begin{array}{l}109.05 \\
(-0.18) \\
107.82 \\
\end{array}$ & $\begin{array}{c}95.46 \\
(-1.11) \\
94.43 \\
\end{array}$ \\
\hline $\begin{array}{l}\mathrm{NiL}_{2} @ \mathrm{RT}^{*} \\
\mathrm{Ni} \\
\mathrm{Cu}\end{array}$ & $\begin{array}{c}6.20 \\
(-1.46) \\
6.25\end{array}$ & $\begin{array}{c}8.01 \\
(-2.42) \\
8.05\end{array}$ & $\begin{array}{c}8.58 \\
(-0.80) \\
8.61\end{array}$ & $\begin{array}{l}71.96 \\
(0.05) \\
70.78\end{array}$ & $\begin{array}{c}79.81 \\
(-0.99) \\
78.64\end{array}$ & $\begin{array}{l}85.59 \\
(2.09) \\
86.27\end{array}$ \\
\hline
\end{tabular}

* The experimental NiL $_{2}$ RT structure has been reported by Voutsas, et al. 30

Overall, it is found that DFT calculations are able to successfully ${ }_{65}$ reproduce the experimental crystal structures with good accuracy, with all differences between the calculated and experimental parameters for the low temperature structures $(<=150 \mathrm{~K})$ under $1.5 \%$. At room temperature, the calculated lattice constants are significantly less than the experimental parameters, as expected. 70 The XDM method has been reported to perform extremely well for calculations of molecular crystals, such as the $\mathrm{C} 21$ reference set ${ }^{31,32}$ and a set of monosaccharide structures ${ }^{31}$. Note that the three calculated $\mathrm{Cu}$ structures starting from the two experimental $\mathrm{Cu}$ structures and the room temperature $\mathrm{Ni}$ structure are 
essentially the same (maximum cell length difference of $0.003 \AA$ and cell angle difference of $\left.0.117^{\circ}\right)$. This is also true of the calculated Ni structures (maximum cell length difference of 0.005 $\AA$ and cell angle difference of $0.105^{\circ}$ ). This is expected as all 5 three experimental structures are isomorphous and the DFT calculations are all at $0 \mathrm{~K}$, which gives confidence that the Quantum ESPRESSO optimiser is performing well.

In Table 3, we report the relative total energies for each metal 10 atom in the four $\mathbf{L}$ oxime structures.

Table 3. Calculated relative energies $(\mathrm{kJ} / \mathrm{mol})$ of the high and low temperature $\mathrm{Cu}$ and $\mathrm{Ni} \mathbf{L}$ oxime complexes.

\begin{tabular}{|l|c|c|}
\hline Structure & \multicolumn{2}{|c|}{ Relative energy (kJ/mol) } \\
\hline & $\mathbf{C u}$ & $\mathbf{N i}$ \\
\hline $\mathrm{CuL}_{2} @ 100 \mathrm{~K}$ & 0.37 & 1.00 \\
\hline $\mathrm{CuL}_{2} @ 150 \mathrm{~K}$ & 0.38 & 1.00 \\
\hline $\mathrm{NiL}_{2} @ 100 \mathrm{~K}$ & 0.00 & 0.00 \\
\hline $\mathrm{NiL}_{2} @ \mathrm{RT}$ & 0.37 & 0.99 \\
\hline
\end{tabular}

15 The results in Table 3 show that the low temperature Ni structure is the most stable structure for both $\mathrm{Ni}$ and $\mathrm{Cu}$ complexes. Not surprisingly, the energies of the other three structures are essentially the same for both $\mathrm{Cu}$ and $\mathrm{Ni}$ as they have all optimised to the same structure as discussed above. The energy differences 20 between the two polymorphs for both $\mathrm{Cu}$ and $\mathrm{Ni}$ are small, although the difference between the two Ni structures is almost three times higher than for $\mathrm{Cu}$.

This small difference between the enthalpies of polymorphs is not 25 unusual. The experimental difference in energy between the $\alpha$ and $\beta$ polymorphs of oxalic acid (corrected to ignore thermal and zero-point effects) is only $0.17 \mathrm{~kJ} / \mathrm{mol}^{32}$, whilst the calculated energy difference between the two forms of aspirin using a similar functional accounting for $\mathrm{vdW}$ interactions and excluding 30 thermal and zero-point effects is $0.18 \mathrm{~kJ} / \mathrm{mol}^{33}$. However, with energy differences this small, the choice of vdW functional can change the calculated relative stabilities ${ }^{33}$. Despite this, the calculated energy differences are consistent with the experimental results as although the $0 \mathrm{~K}$ calculations predict that both the $\mathrm{Cu}$

35 and $\mathrm{Ni}$ containing complex are most stable in the $100 \mathrm{~K} \mathrm{Ni}$ experimental structure, the energy difference in the case of $\mathrm{Cu}$ is only $0.37 \mathrm{~kJ} / \mathrm{mol}$ which is significantly less than the $K_{\mathrm{B}} \mathrm{T}$ value of $0.83 \mathrm{~kJ} / \mathrm{mol}$ at $100 \mathrm{~K}$.

${ }_{40}$ We have demonstrated that the energy difference between the two structural types is small. We now turn to Hirshfeld surfaces to characterise the geometric differences between the two structures. As illustrated in Figure 1, the differences appear to be slight, which is why we developed the idea of a difference fingerprint ${ }_{45}$ plot outlined in the Methodology section. Before applying difference fingerprint plots to the new structures presented here, it is instructive to utilise them to highlight the differences between two polymorphs whose fingerprint plots have already been discussed in the literature. We chose the system 2-chloro-450 nitrobenzoic acid (2c4n) that has two known polymorphs ${ }^{34}$; both crystallise in $P 2_{1} / c$ and form I has a Z' of 1 whilst form II has a Z' of 4. Spackman and Jayatilaka ${ }^{35}$ have undertaken an extensive analysis of these two structures. The fingerprint plots of the five symmetry unique molecules generated directly from the Hirshfeld ${ }_{55}$ surface calculated in CrystalExplorer using our programs/scripts are reproduced in Figure 2.

Spackman and Jayatilaka concluded that the differences between the two modifications from comparing these fingerprint plots are 60 that:

1. The fingerprint plots for each of the four symmetry independent molecules in form II are more similar to each other than they are for the single symmetry independent molecule in form I.

2. All of the symmetry independent molecules in form II have increased intensity around $\mathrm{d}_{\mathrm{i}} \approx \mathrm{d}_{\mathrm{e}} \approx 2.0 \AA$, which indicates that they participate in a planar stacking arrangement (in this case $\pi \ldots \pi$ stacking), whereas no such arrangement is present in form I.

The two major similarities they identified are:

1. The dominant interaction in both forms is a cyclic hydrogen bond characteristic of carboxylic acids represented by a pair of spikes at the bottom left of the fingerprint plot.

2. All molecules participate in $\mathrm{Cl}$...H hydrogen bonds characterized by a pair of much smaller spikes in the middle of the fingerprint plot at $\mathrm{d}_{\mathrm{i}} \approx 2.0, \mathrm{~d}_{\mathrm{e}} \approx 1.2$ and $\mathrm{d}_{\mathrm{i}}$ $\approx 1.2, \mathrm{~d}_{\mathrm{e}} \approx 2.0$. These are particularly clear in the fingerprint for molecule $\mathrm{C}$ in form II.
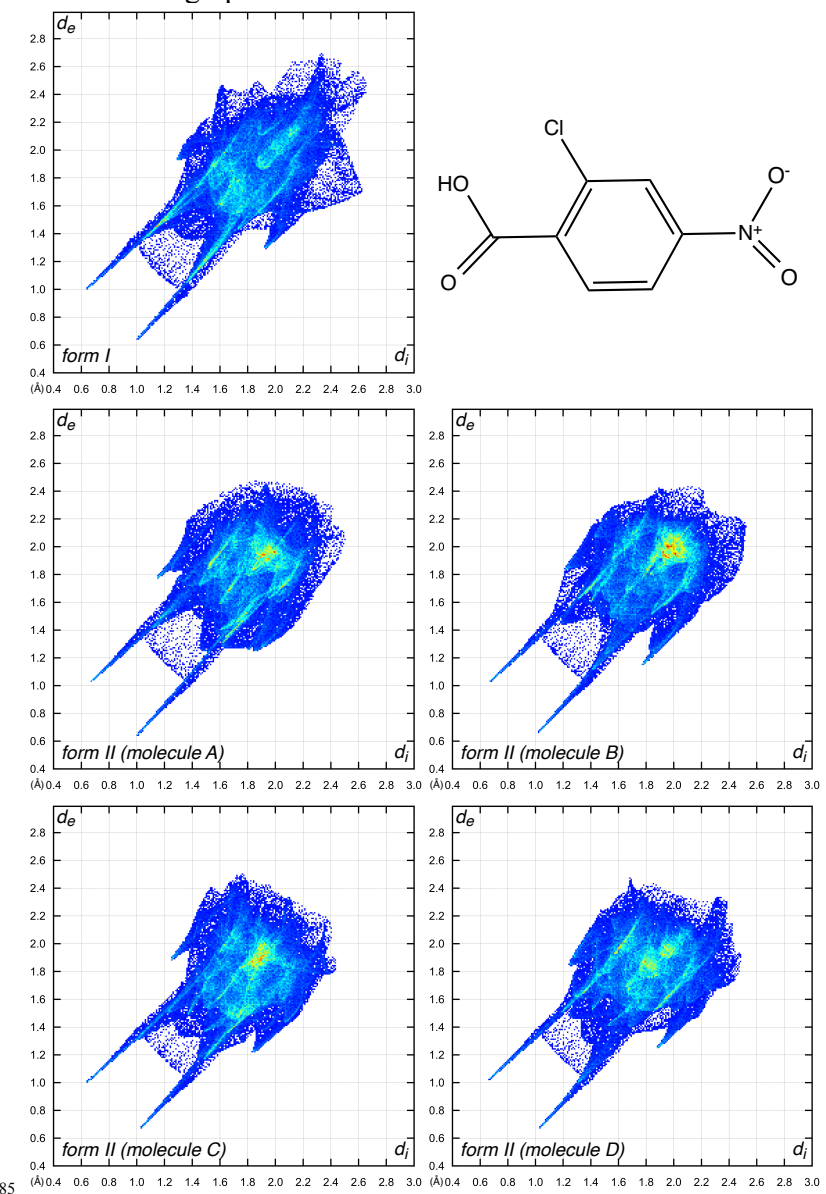
Figure 2. Fingerprint plots for the single symmetry independent molecule in form I of 2c4n and four symmetry independent molecules in form II.

Can the use of difference fingerprint plots make these differences clearer and provide additional insights? In Figure 3, the 5 difference between the fingerprint plot of the molecule in form 1 and each of the molecules in form 2 is displayed.
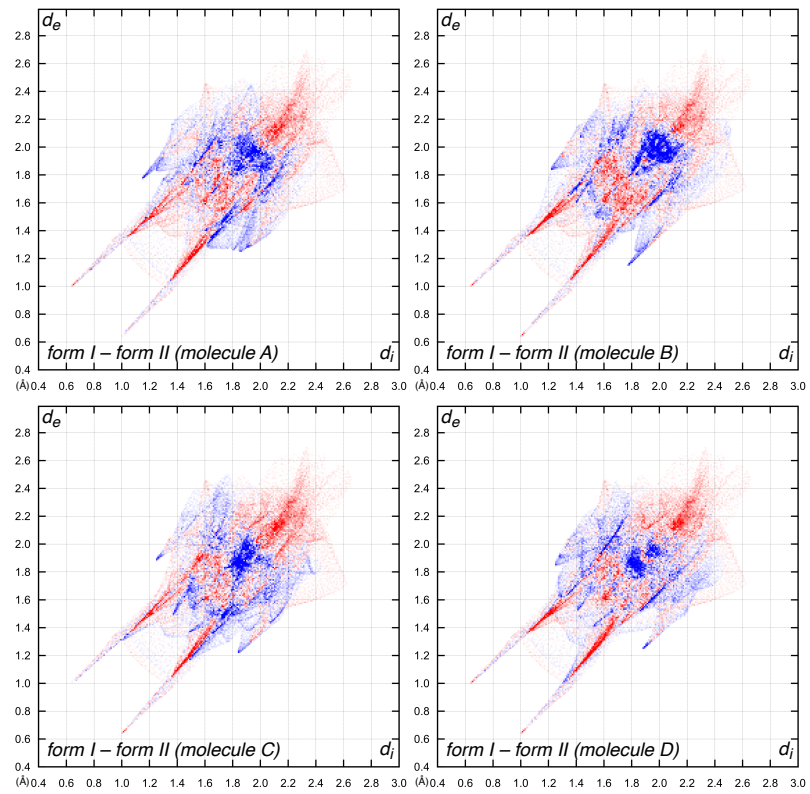

Figure 3. Difference fingerprint plots between the single molecule of 10 form I of $\mathbf{2 c 4 n}$ and the four molecules in form II.

Areas in blue are negative i.e. these areas are more intense in the form II fingerprint compared to the form I fingerprint. Thus, the strong blue areas in Figure 3 clearly illustrate that the form II molecules all have greater prevalence of planar stacking motifs 15 compared to form I. Red then highlights areas with more intensity in the form I structure compared to form II. All of the difference plots have red areas at the top right because form I has a feature at these high $d_{i}$ and $d_{e}$ values (primarily due to interactions involving $\mathrm{Cl}$ ) which is not present in the form II fingerprints as 20 clearly shown in Figure 2. The other red feature in all the plots in Figure 3 is the spikes within the cyclic carboxylic acid spikes. These spikes finish at $\mathrm{d}_{\mathrm{i}} \approx 1.3 \AA, \mathrm{d}_{\mathrm{e}} \approx 1.0 \AA$ and $\mathrm{d}_{\mathrm{i}} \approx 1.0 \AA, \mathrm{d}_{\mathrm{e}} \approx$ $1.4 \AA$. These are due to the presence of shorter $\mathrm{H}^{\cdots} \mathrm{O}-\mathrm{N}$ distances in form I (two less than $2.5 \AA$ ) compared to all the molecules in ${ }_{25}$ form II (none less than $2.5 \AA$ ).

Figure 3 only shows the differences between the molecule in form I with those in form II. However for $n$ molecules there are $n(n-1) / 2$ difference fingerprint plots (the denominator of 2 is 30 because for two fingerprint plots $A$ and $B, B-A$ is simply - $(A-B)$ i.e. it is $A-B$ with the colours reversed). For $2 \mathbf{c 4 n}$ with 5 symmetry independent molecules in the two polymorphs, $n=5$ and thus there are 10 difference fingerprint plots to be considered. Although a visual analysis of the difference fingerprint plots can 35 provide useful qualitative information about where the molecular environments differ, can these differences be quantified? The simplest measure is to sum the absolute value of each point in the difference plot. This measure is similar to one of the three measures (the Manhattan metric) defined in the work of ${ }_{40}$ Latosińska et al ${ }^{13}$, although the magnitudes of our measure are clearly different; we note that the details of their procedure are yet to be published. Table 4 calculates this quantity for the 10 difference plots of $2 \mathbf{c} 4 \mathbf{n}$.

${ }_{45}$ Table 4. Sum of the absolute values of the difference plots of $2 \mathbf{c} 4 \mathbf{n}$.

\begin{tabular}{|l|l|l|l|l|}
\hline & Form II A & Form II B & Form II C & Form II D \\
\hline Form I & 73.1 & 75.9 & 75.0 & 72.3 \\
\hline Form II A & & 66.8 & 63.1 & 64.6 \\
\hline Form II B & & & 70.2 & 64.2 \\
\hline Form II C & & & & 62.7 \\
\hline
\end{tabular}

The magnitude of these sums is surprisingly large given that comparing two plots where there are no areas in common would lead to a sum of 200 due to the normalisation of the individual 50 fingerprint plots. The results in Table 4 support the observation from the visual comparison of the fingerprint plots by Spackman and Jayatilaka that each of the four symmetry independent molecules in form II are more similar to each other than they are to the single symmetry independent molecule in form I as the ${ }_{55}$ values in row 1 of Table 4 are greater than the values in the other rows. However, there are significant differences in the values obtained for the difference fingerprint plots obtained between the symmetry independent molecules in form II, with the difference fingerprint plot between independent molecules B and C closer to 60 the form I - form II values. Thus, in Figure 4, the difference fingerprint plot of independent molecules $\mathrm{B}$ and $\mathrm{C}$ in form II are reproduced along with the difference fingerprint plot for form II independent molecules $\mathrm{C}$ and $\mathrm{D}$, which is the plot with the lowest sum of absolute values.

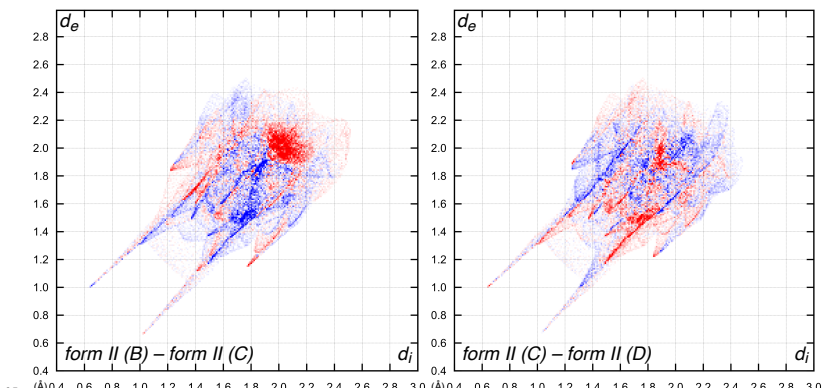

(a)

(b)

Figure 4. Difference fingerprint plots between the independent molecules (a) B and C (b) C and D of form II of $2 \mathbf{c} 4 \mathbf{n}$.

The figure shows that there are significantly more differences in ${ }_{70}$ Figure 4(a) than Figure 4(b) and that the former is more similar to the plots in Figure 3. Consequently, the sum of the absolute values of a difference plot is a good measure of the magnitude of the differences between two fingerprint plots and has brought out differences in $\mathbf{2 c 4 n}$ that cannot be discerned simply by looking at 75 the fingerprint plots in Figure 2.

We now turn to the $\mathrm{Cu}$ and $\mathrm{Ni} \mathbf{L}$ complexes. The fingerprint plots corresponding to the experimental structures are given in Figure 5. Simple visual inspection shows that the three isomorphous 80 structures, high temperature $\mathrm{Ni}_{2}$ and the two $\mathrm{CuL}_{2}$ structures, are similar and notably different to the plot for the low temperature $\mathrm{NiL}_{2}$ structure. The dominant feature in the three similar fingerprint plots is at $\mathrm{d}_{\mathrm{i}} \approx 1.8, \mathrm{~d}_{\mathrm{e}} \approx 1.8$ consistent with the 
planar stacking arrangement observed.

The Hirshfeld surfaces emphasize that the planar stacking causes a particularly close approach between the phenol $\mathrm{C}$ atom and the 5 oxime $\mathrm{C}$ atom of the neighboring molecule in all four structures $\left(3.335 \AA 100 \mathrm{~K} \mathrm{NiL}_{2}, 3.302 \AA \mathrm{RT} \mathrm{NiL}_{2}, 3.240 \AA 100 \mathrm{~K} \mathrm{CuL}_{2}\right.$, $3.258 \AA 150 \mathrm{~K} \mathrm{CuL}_{2}$ ). The unique low temperature Ni structure also shows a close approach between a p-methyl $\mathrm{H}$ atom and a neighbouring oxime $\mathrm{O}$ atom (C...O, $3.633 \AA$ ), which is not 10 observed in the other systems.
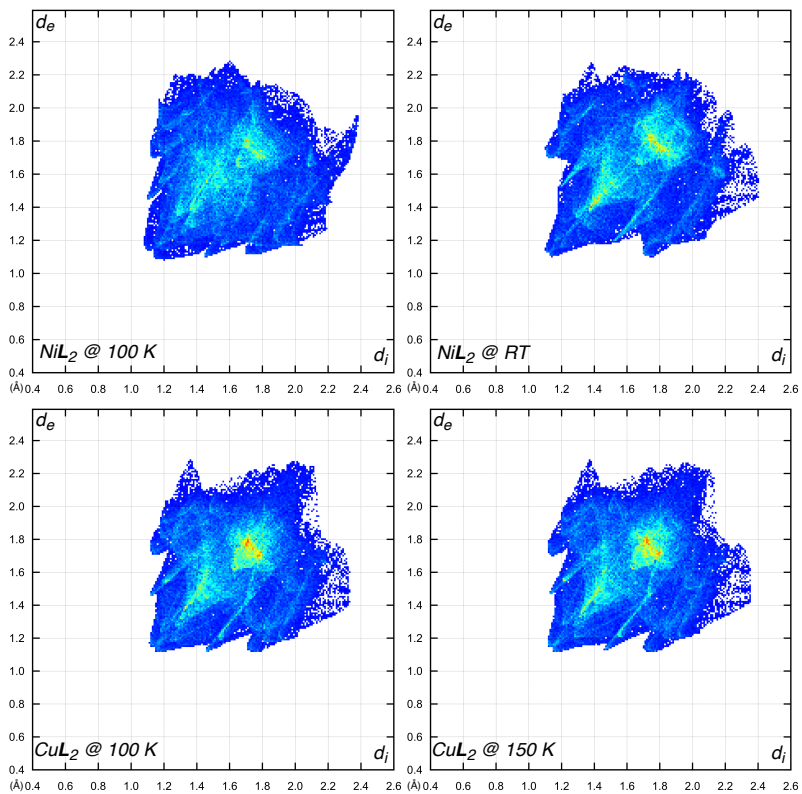

Figure 5. Fingerprint plots for the $\mathrm{CuL}_{2}$ and $\mathrm{Ni}_{2}$ complexes discussed in this paper.

20 In Figure 6, the difference plots between all the experimental structures are displayed and the corresponding sums of absolute values are provided in Table 5. Given that three of the four structures are isostructural, the calculated absolute values immediately provide some interesting insights. The lowest sum of

${ }_{25}$ absolute values by a large margin is for the isostructural $\mathrm{Cu}$ structures determined at 100 and $150 \mathrm{~K}$. This is clear in Figure 6(f), where there are no large areas of either blue or red in the corresponding fingerprint difference plot. It is noteworthy however that there are differences, despite the two fingerprint ${ }_{30}$ plots appearing identical (Figure 5).

Table 5. Sum of the absolute values of the difference plots of the $\mathrm{CuL}_{2}$ and $\mathrm{Ni}_{2}$ complexes discussed in this paper

\begin{tabular}{|l|c|c|c|}
\hline & $\mathrm{NiL}_{2} @ \mathrm{RT}$ & $\mathrm{CuL}_{2} @ 100 \mathrm{~K}$ & $\mathrm{CuL}_{2} @ 150 \mathrm{~K}$ \\
\hline $\mathrm{NiL}_{2} @ 100 \mathrm{~K}$ & 60.8 & 56.8 & 56.7 \\
\hline $\mathrm{NiL}_{2} @ \mathrm{RT}$ & & 59.1 & 56.8 \\
\hline $\mathrm{CuL}_{2} @ 100 \mathrm{~K}$ & & & 41.1 \\
\hline
\end{tabular}

35 Although it is not surprising that the highest sum is observed in one of the difference plots between $\mathrm{Ni}_{2}$ at $100 \mathrm{~K}$ and the three other structures that are isostructural with each other, the size of the sum of absolute values of the difference plots between the three isostructural structures themselves are of a similar 40 magnitude. In fact, by this measure, the difference between the isostructural $\mathrm{CuL}_{2}$ at $100 \mathrm{~K}$ and $\mathrm{NiL}_{2}$ at $\mathrm{RT}$ is slightly larger than the difference between the non-isostructural $\mathrm{CuL}_{2}$ at $100 \mathrm{~K}$ and $\mathrm{NiL}_{2}$ at $100 \mathrm{~K}$.

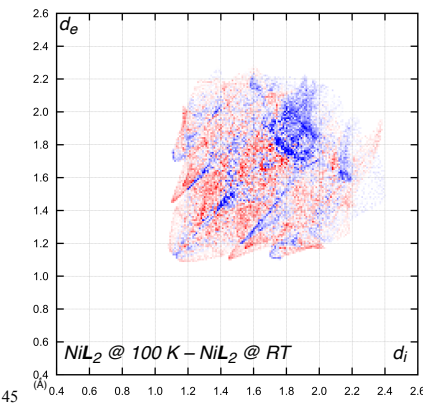

(a)

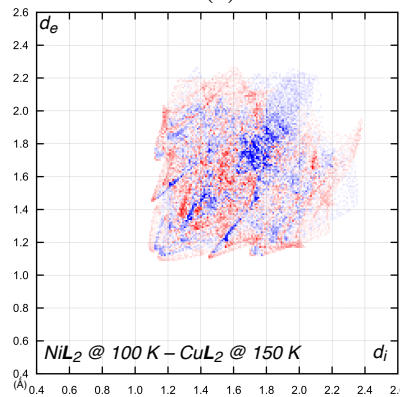

(c)

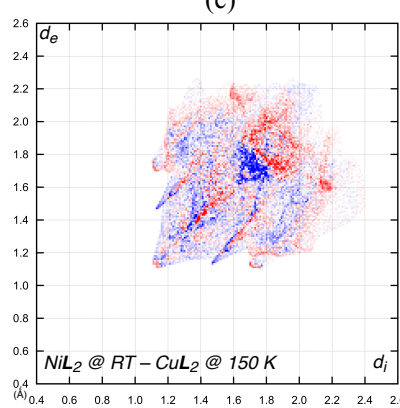

(e)

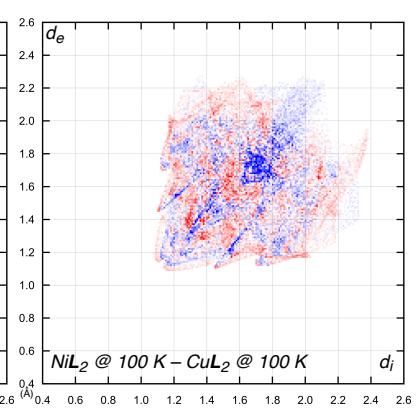

(b)

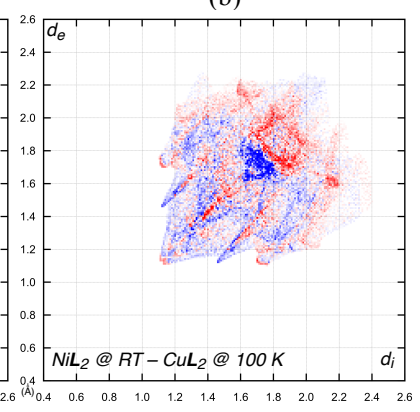

(d)

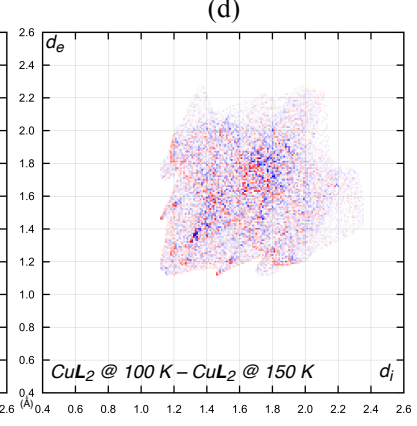

(f)

Figure 6. All possible difference fingerprint plots of the experimentally determined $\mathrm{ML}_{2}$ structures.

The difference plots between the three isostructural structures and $\mathrm{NiL}_{2}$ at $100 \mathrm{~K}$ (Figure 6(a-c)) show that the differences with the ${ }_{55}$ two $\mathrm{Cu}$ structures are very similar, with both $\mathrm{Cu}$ fingerprints having significantly more intensity centred around $\mathrm{d}_{\mathrm{i}} \approx 1.7, \mathrm{~d}_{\mathrm{e}} \approx$ 1.7 i.e. the biggest difference isn't due to the characteristic signature of planar stacking at $\mathrm{d}_{\mathrm{i}} \approx 1.8, \mathrm{~d}_{\mathrm{e}} \approx 1.8$; rather the $\mathrm{Cu}$ structures have more intensity immediately below this area. The ${ }_{60}$ difference between the two $\mathrm{Ni}$ structures is different with $\mathrm{NiL}_{2}$ at RT having significantly more intensity centred around $\mathrm{d}_{\mathrm{i}} \approx 1.9, \mathrm{~d}_{\mathrm{e}}$ $\approx 1.9$, with the other Ni structure having a higher density at $\mathrm{d}_{\mathrm{i}} \approx$ $1.7, \mathrm{~d}_{\mathrm{e}} \approx 1.7$. These differences are not obvious from Figure 5 and reflect the very small changes in the phenol $\mathrm{C}$ atom to oxime $\mathrm{C}$ ${ }_{65}$ atom intermolecular distances noted earlier, with the two $\mathrm{Cu}$ structures having distances less than the Ni structures i.e. small changes in packing characterized by a single intermolecular 
distance manifest themselves in the fingerprint plot, but only become apparent to the human eye in the difference fingerprint plot.

5 The difference fingerprint plots of $\mathrm{NiL}_{2}$ at $\mathrm{RT}$ with the two $\mathrm{Cu}$ structures (Figure $6(\mathrm{~d}, \mathrm{e})$ ), all of which are isostructural, show that the $\mathrm{Cu}$ fingerprints have significantly more intensity centred around $\mathrm{d}_{\mathrm{i}} \approx 1.7, \mathrm{~d}_{\mathrm{e}} \approx 1.7$ whereas the $\mathrm{NiL}_{2}$ at $\mathrm{RT}$ has higher intensity centred around $\mathrm{d}_{\mathrm{i}} \approx 1.9, \mathrm{~d}_{\mathrm{e}} \approx 1.9$, again consistent with 10 the short phenol $\mathrm{C}$ atom to oxime $\mathrm{C}$ atom intermolecular distances.

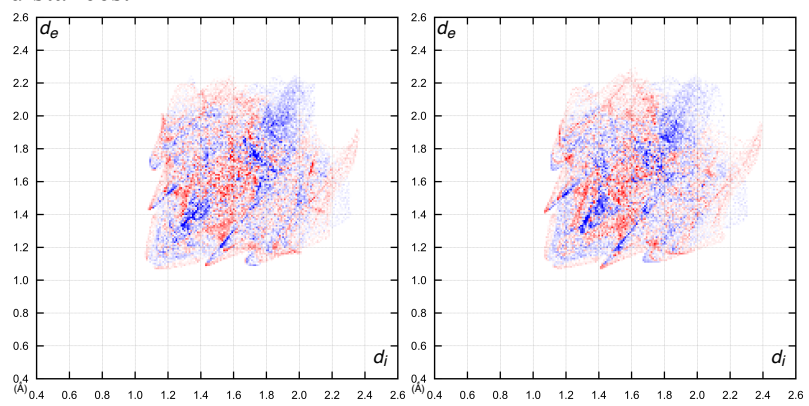

(a)

(b)

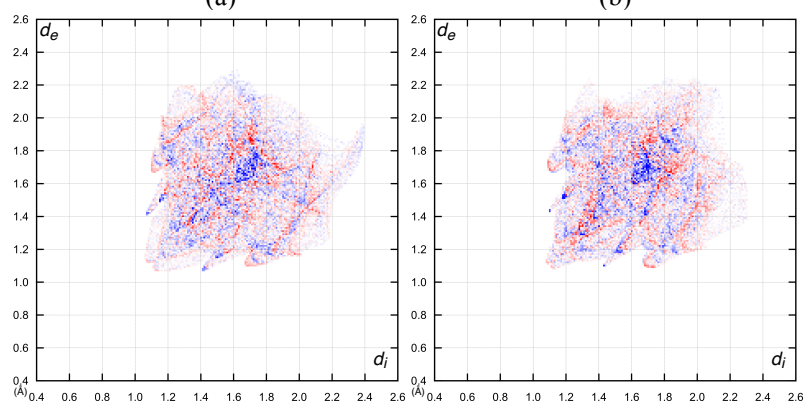

(c)

(d)

Figure 7. Difference fingerprint plots of the calculated $\mathrm{ML}_{2}$ structures. The difference plots between (a) $\mathrm{Ni}$ and (b) $\mathrm{Cu}$ in the two structural types. The difference between the calculated $\mathrm{Ni}$ and $\mathrm{Cu}$ structures in the (c) $\mathrm{NiL}_{2} 100 \mathrm{~K}$ structure and (d) $\mathrm{NiL}_{2} \mathrm{RT}$ structure.

20

In Figure 7, the difference plots between the four calculated structures are displayed. The absolute sums of the differences of each metal in the two structural types in Figure $7(\mathrm{a}, \mathrm{b})$ are 55.6 and 54.3 respectively and the difference plots look very similar.

${ }_{25}$ These difference plots are most similar to Figure 6(a), the difference plot for the experimental $\mathrm{Ni}$ structures, although it must be noted that the calculated structures are both at $0 \mathrm{~K}$, whereas the experimental structures are at $100 \mathrm{~K}$ and $\mathrm{RT}$ respectively, leading to the greater magnitude differences 30 observed in Figure 6(a). For the plots for difference between the $\mathrm{Cu}$ and $\mathrm{Ni}$ in a given structural type in Figure $7(\mathrm{c}, \mathrm{d})$, the absolute sums of the differences are 47.9 and 47.3 respectively. This immediately shows that the differences due to the different structural types are much larger than the differences associated 35 with changing the coordinating metal ion. Although this was also evident in the differences in experimental structures, the effect is much less marked (a difference in absolute values of $\sim 4$ in the experimental structures vs $\sim 9$ in the calculated structures), presumably because of the different temperatures of the crystal 40 structure determinations. There is no experimental equivalent to
Figure 7(c) as there is no $\mathrm{Cu}$ equivalent of the $\mathrm{NiL}_{2} 100 \mathrm{~K}$ structure. However, for Figure 7(d), the closest experimental equivalent (albeit the experimental structures being determined at $150 \mathrm{~K}$ and RT) is Figure 6(e) and the two plots are similar in that 45 there is a blue area at $\mathrm{d}_{\mathrm{i}} \approx 1.7, \mathrm{~d}_{\mathrm{e}} \approx 1.7$, with a concentration of red immediately above the blue area.

The similarities between the difference plots derived from calculated structures compared to those derived from so experimental structures suggest that the simulations are reproducing the fine detail of the packing in the structural types. A more direct way to assess the accuracy of the simulations is to calculate difference fingerprint plots between a calculated and experimental structure. The lower the temperature of the 5 experimental structure, the better the anticipated agreement. Thus, in Figure 8 , the difference plots between the calculated structures and the $100 \mathrm{~K}$ experimental structures are reproduced. The absolute sums of the differences are 47.5 for the $\mathrm{NiL}_{2} 100 \mathrm{~K}$ structure and 45.8 for the $\mathrm{CuL}_{2} 100 \mathrm{~K}$ structure (which is 60 isostructural with the other two structures). These are the two lowest absolute sums of differences after the difference between the two $\mathrm{Cu}$ structures (which are isostructural at $100 \mathrm{~K}$ and 150 $\mathrm{K}$ ) in Figure 6(f). The two plots in Figure 8 have little structure, again in common with Figure 6(f), illustrating that the differences ${ }_{65}$ between the calculated and experimental structures is small and are of the same order as differences between the experimental determinations at $100 \mathrm{~K}$ and $150 \mathrm{~K}$. This assessment of the quality of the simulated structures would not be possible without the use of difference fingerprint plots.

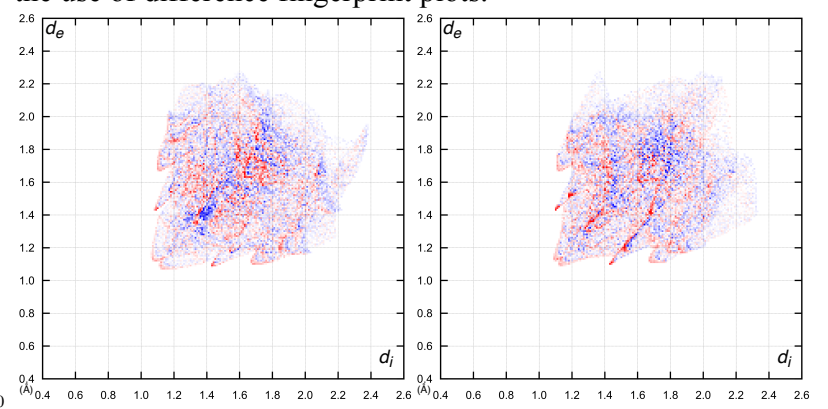

(a)

(b)

Figure 8. Difference fingerprint plots between calculated $(0 \mathrm{~K})$ and experimental $(100 \mathrm{~K})$ structures of (a) $\mathrm{Ni}_{2}$ and (b) $\mathrm{CuL}_{2}$.

\section{Conclusions}

75 The observation of temperature-dependent polymorphism in $\mathrm{NiL}_{2}$, but not $\mathrm{CuL}_{2}$, is consistent with the calculated relative energies of the structures, albeit with small energy differences. To examine structural differences in these systems in detail, we were driven to develop the software needed to generate difference 80 fingerprint plots derived from Hirshfeld surfaces. Difference fingerprint plots are simply the result of subtracting one fingerprint plot from another. The resulting plots were found to reveal differences between structures that are not apparent upon visual inspection of the individual fingerprint plots. In addition, ${ }_{85}$ summing the absolute values of a difference fingerprint plot provides a quantitative measure of the difference between two structures. This summed value complements the qualitative conclusions drawn from visual inspection of the plots. This 
quantitative measure may be particularly useful for providing a consistent means of comparing calculated and experimental structures, as well as classifying structures produced in polymorph prediction.

\section{Acknowledgments}

PR and ALR would like to thank the ARC for funding (FT130100463 and DP140101776, respectively). We would also like to thank Prof. Mark Spackman for fruitful discussions in the early stages of this work. This work was supported by resources 10 provided by the Pawsey Supercomputing Centre with funding from the Australian Government and the Government of Western Australia and with the assistance of resources from the National Computational Infrastructure (NCI), which is also supported by the Australian Government

\section{${ }_{15}$ Notes and references}

${ }^{a}$ Curtin Institute for Computation \& Department of Chemistry. Curtin University. GPO Box U 1987, Perth WA, 6845.

${ }^{b}$ CSIRO Mineral Resources Flagship, PO Box 7229, Karawara, Western Australia 6152, Australia

${ }_{20}^{c}$ Nanochemistry Research Institute \& Department of Chemistry. Curtin University. GPO Box U 1987, Perth WA, 6845.

${ }^{d}$ M310, School of Chemistry and Biochemistry, University of Western Australia, Perth, Western Australia 6009, Australia

25 Email: andrew.rohl@curtin.edu.au

$\dagger$ Electronic Supplementary Information (ESI) available: Synthesis and structure determination of $\left[\mathrm{Ni}\left(\mathrm{L}-\mathrm{NO}_{2}\right)_{2}(\mathrm{dmso})_{2}\right]$. See DOI: $10.1039 / \mathrm{b} 000000 \mathrm{x} /$

\$ Footnotes should appear here. These might include comments relevant 30 to but not central to the matter under discussion, limited experimental and spectral data, and crystallographic data.

1 J. J. McKinnon, M. A. Spackman and A. S. Mitchell, Acta Crystallographica Section B: Structural Science, 2004, 60, 627668.

2 M. A. Spackman and J. J. McKinnon, Crystengcomm, 2002, 4, 378-392.

3 J. J. McKinnon, F. P. A. Fabbiani and M. A. Spackman, Cryst Growth Des, 2007, 7, 755-769.

404 S. V. S. Bebiano, M. T. S. Rosado, R. A. E. Castro, M. R. Silva, J. Canotilho, T. M. R. Maria and M. E. S. Eusébio, Journal of Molecular Structure, 2014, 1078, 10-19.

5 Y.-H. Luo, Q.-L. Liu, L.-J. Yang, W. Wang, Y. Ling and B.-W. Sun, Research on Chemical Intermediates, 2015, 1-14.

456 S. Bergantin and M. Moret, Cryst Growth Des, 2012, 12, 60356041

7 S. K. Rai, P. Singh, S. Khanam and A. K. Tewari, New J. Chem., 2016, 40, 5577-5587.

8 M. T. Kaczmarek and M. Kubicki, Acta Cryst B., 2014, 70, $792-$ 800.

9 A. L. Rohl, M. Moret, W. Kaminsky, K. Claborn, J. J. McKinnon and B. Kahr, Cryst Growth Des, 2008, 8, 4517-4525.

10 B. Schatschneider and J.-J. Liang, J.Chem. Phys., 2011, 135, 164508-12.

5511 A. Parkin, G. Barr, W. Dong, C. J. Gilmore, D. Jayatilaka, J. J. McKinnon, M. A. Spackman and C. C. Wilson, Crystengcomm, 2007, 9, 648

12 A. Collins, C. C. Wilson and C. J. Gilmore, Crystengcomm, 2010, 12, 801-809.

6013 J. N. Latosińska, M. Latosińska, M. Szafrański, J. Seliger and V. Žagar, Cryst Growth Des, 2016, 16, 4336-4348.

14 V. M. Hultgren, R. L. Beddoes, D. Collison, M. Helliwell, I. M. Atkinson, C. D. Garner, L. F. Lindoy and P. A. Tasker, Chemical Communications, 2001, 573-574.

6515 D. D'Alessio, D. M. Lombardo, J. G. Vaughan, B. W. Skelton, K.
R. Barnard and M. I. Ogden, Dalton Trans., 2015, 44, 7163-7168.

16 K. R. Barnard, D. W. Shiers, M. J. McIldowie, B. W. Skelton, M. I. Ogden and T. M. McCoy, Ind. Eng. Chem. Res., 2014, 53, 8208-8214.

7017 K. R. Barnard, G. L. Nealon, M. I. Ogden and B. W. Skelton, Solvent Extraction and Ion Exchange, 2010, 28, 778-792.

18 A. I. Vogel, B. S. Furniss, A. J. Hannaford, P. W. G. Smith and A. R. Tatchell, Vogel's Textbook of Practical Organic Chemistry, John WIley \& Sons, New York, 5 edn. 1989.

7519 G. M. Sheldrick, Acta Cryst. C, 2015, 71, 3-8.

20 P. Giannozzi, S. Baroni, N. Bonini, M. Calandra, R. Car, C. Cavazzoni, D. Ceresoli, G. L. Chiarotti, M. Cococcioni, I. Dabo, A. Dal Corso, S. de Gironcoli, S. Fabris, G. Fratesi, R. Gebauer, U. Gerstmann, C. Gougoussis, A. Kokalj, M. Lazzeri, L. MartinSamos, N. Marzari, F. Mauri, R. Mazzarello, S. Paolini, A. Pasquarello, L. Paulatto, C. Sbraccia, S. Scandolo, G. Sclauzero, A. P. Seitsonen, A. Smogunov, P. Umari and R. M. Wentzcovitch, J Phys-Condens Mat, 2009, 21, 395502.

21 P. E. Blöchl, Phys. Rev. B, 1994, 50, 17953-17979.

8522 N. Holzwarth, A. R. Tackett and G. E. Matthews, Computer Physics Communications, 2001, 135, 329-347.

23 A. D. Becke and E. R. Johnson, J.Chem. Phys., 2007, 127, 124108.

24 A. Otero-de-la-Roza and E. R. Johnson, J.Chem. Phys., 2012, 136, $90 \quad 174109$.

25 A. D. Becke, J.Chem. Phys, 1986, 85, 7184.

26 J. Perdew, K. Burke and M. Ernzerhof, Phys Rev Lett, 1996, 77, 3865-3868.

27 S. K. Wolff, D. J. Grimwood, J. J. McKinnon, M. J. Turner, D.

95 Jayatilaka and M. A. Spackman, 2012. CrystalExplorer (Version 3.1), University of Western Australia.

28 P. Raiteri, https://doi.org/10.5281/zenodo.55610, 2016.

29 R. S. Forgan, B. D. Roach, P. A. Wood, F. J. White, J. Campbell, D. K. Henderson, E. Kamenetzky, F. E. McAllister, S. Parsons, E. 100 Pidcock, P. Richardson, R. M. Swart and P. A. Tasker, Inorg. Chem., 2011, 50, 4515-4522.

30 G. P. Voutsas, K. G. Keramidas, E. Dova, M. Lalia-Kantouri and M. Hartophylles, Zeitschrift für Kristallographie - New Crystal Structures, 1999, 214, 33-34.

10531 D. J. Carter and A. L. Rohl, J. Chem. Theory Comput, 2014, 10, 3423-3437.

32 A. Otero-de-la-Roza and E. R. Johnson, J.Chem. Phys., 2012, 137, 054103 .

33 A. M. Reilly and A. Tkatchenko, Phys Rev Lett, 2014, 113,

$110 \quad$ 055701-5.

34 I. Barsky, J. Bernstein, P. W. Stephens and K. H. Stone, New J. Chem., 2008, 32, 1747-1753.

35 M. A. Spackman and D. Jayatilaka, Crystengcomm, 2009, 11, 19.

8 | Journal Name, [year], [vol], 00-00 


\title{
Difference Hirshfeld fingerprint plots: A tool for studying polymorphs
}

\author{
Damien J. Carter, Paolo Raiteri, Keith R. Barnard, Rhian Gielink, Mauro Mocerino, \\ Brian W. Skelton, Jamila G. Vaughan, Mark I. Ogden, and Andrew L. Rohl
}

\author{
Supplementary Information
}

\section{Synthesis and structure determination of $\left[\mathrm{Ni}\left(\mathrm{L}-\mathrm{NO}_{2}\right)_{2}(\mathrm{dmso})_{2}\right]$}

\section{Synthesis}

$\mathrm{Ni}\left(\mathrm{NO}_{3}\right)_{2} .6 \mathrm{H}_{2} \mathrm{O}(0.0321 \mathrm{~g}, 0.11 \mathrm{mmol})$ was dissolved in ethyl acetate $(10 \mathrm{~mL})$ with dibutylphosphate ( $40 \mu \mathrm{L}, 0.20 \mathrm{mmol}$ ). The yellow-green solution was examined using UV-Vis spectroscopy. Ketoxime LH (0.7452 g, $4.5 \mathrm{mmol})$ was dissolved in ethyl acetate $(25 \mathrm{~mL})$. The ketoxime solution $2.5 \mathrm{~mL} 0.18 \mathrm{M} 0.45 \mathrm{mmol})$ was added to the metal/acid solution and mixed and the resulting green solution was re-examined via UV-Vis spectroscopy. After 24 hours the solution had darkened to dark yellow and a green jelly-like precipitate had formed. The precipitate was isolated and was found to be insoluble in dichloromethane, methanol, water, chloroform, acetone and ethyl acetate. The green precipitate was eventually dissolved in DMSO to give a yellow solution which was left to sit for several days and afforded red diamond shaped crystals.

\section{Crystallography}

The crystal data for $\left[\mathrm{Ni}\left(\mathbf{L}-\mathrm{NO}_{2}\right)_{2}(\mathrm{dmso})_{2}\right]$ are summarized in Table $\mathrm{S} 1$ with the structure depicted in Fig. S1 where ellipsoids have been drawn at the 50\% probability level. Hydrogen bonding geometries are given in Table S2. Crystallographic data for the structures were collected at 100(2) $\mathrm{K}$ on an Oxford Diffraction Xcalibur diffractometer using Mo $\mathrm{K} \alpha$ radiation. Following analytical absorption corrections and solution by direct methods, the structure was refined against $F^{2}$ with full-matrix least-squares using the program SHELXL-97 ${ }^{1}$. The hydroxyl hydrogen atom was clearly observed in later difference maps and was refined without restraints. All remaining hydrogen atoms were added at calculated positions and refined by use of a riding model. The isotropic displacement parameters were based on the equivalent parameter of the parent atom. Anisotropic displacement parameters were employed for the non-hydrogen atoms. 


\section{Results}

The results of the structure determination were consistent with the formulation $[\mathrm{Ni}(\mathrm{L}-$ $\left.\left.\mathrm{NO}_{2}\right)_{2}(\mathrm{dmso})_{2}\right]$. The ketoxime ligand $\mathrm{HL}$ is presumed to have been nitrated as a result of strong heating in DMSO in the presence of nickel nitrate, converting the ligand to 2-hydroxy-5-methyl-3-nitroacetophenoneoxime $\left(\mathrm{HL}^{\left.-\mathrm{NO}_{2}\right)}\right.$. The molecule is situated on a crystallographic inversion centre. The oxime hydroxyl hydrogen atom is involved in bifurcated hydrogen bonds to the coordinated phenolic oxygen atom and to one of the oxygen atoms of the nitro group of the other ligand.

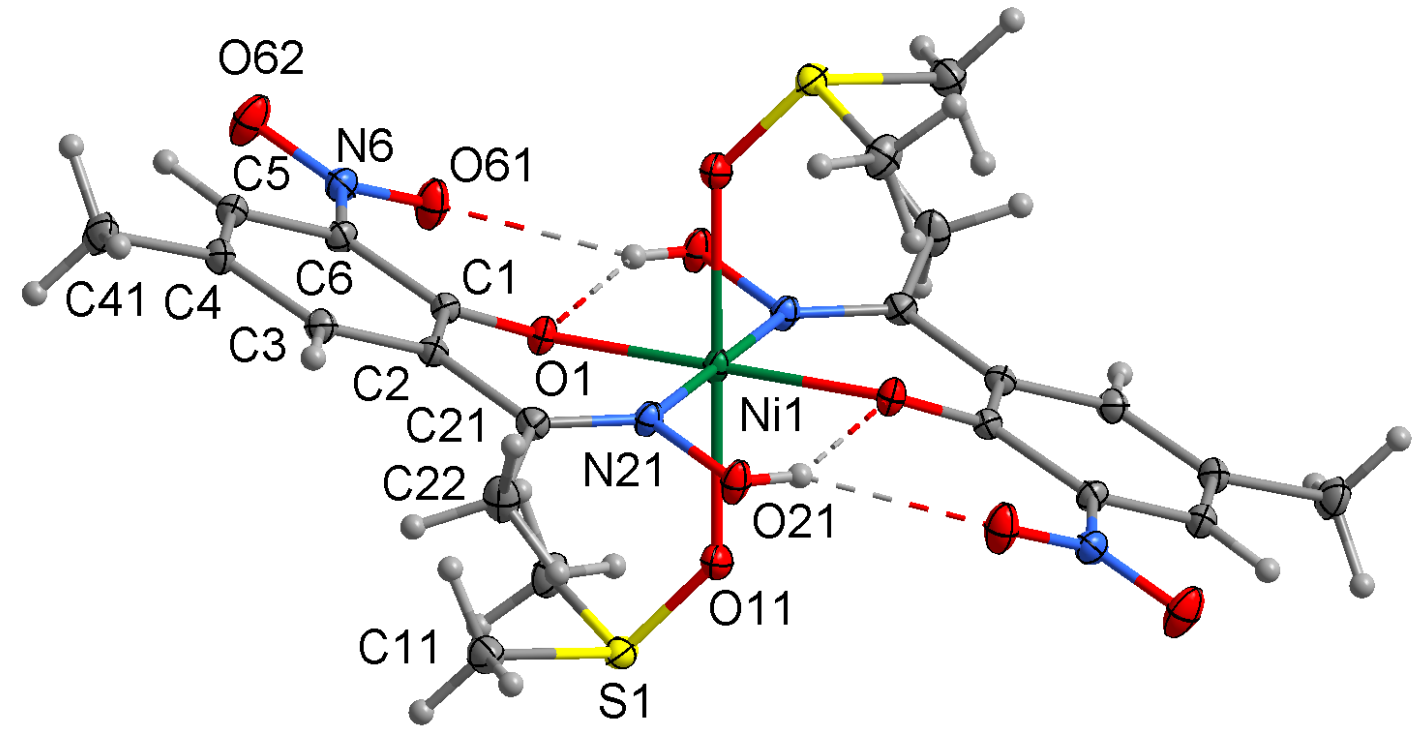

Fig. S1 Structure of the molecule of $\left[\mathrm{Ni}\left(\mathrm{L}-\mathrm{NO}_{2}\right)_{2}(\mathrm{dmso})_{2}\right]$ showing the numbering scheme and the intramolecular hydrogen bonding. 
Table S1. Crystal data and structure refinement for $\left[\mathrm{Ni}\left(\mathbf{L}-\mathrm{NO}_{2}\right)_{2}(\mathrm{dmso})_{2}\right] \mathrm{CCDC}=1526949$.

Empirical formula

Formula weight

Temperature

Wavelength

Crystal system

Space group

Unit cell dimensions

Volume

Z

Density (calculated)

Absorption coefficient

$\mathrm{F}(000)$

Crystal size

$\theta$ range for data collection

Index ranges

Reflections collected

Independent reflections

Completeness to $\theta=33.50^{\circ}$

Absorption correction

Max. and min. transmission

Refinement method

Data / restraints / parameters

Goodness-of-fit on $F^{2}$

Final R indices $[I>2 \sigma(I)]$

$\mathrm{R}$ indices (all data)

Largest diff. peak and hole
$\mathrm{C}_{22} \mathrm{H}_{30} \mathrm{~N}_{4} \mathrm{NiO}_{10} \mathrm{~S}_{2}$

633.33

100(2) K

$0.71073 \AA$

Monoclinic

$P 2{ }_{1} / c$

$a=10.8252(10) \AA$

$b=7.7396(3) \AA$

$c=15.3660(6) \AA$

$\beta=95.439(5)^{\circ}$

1281.61(14) $\AA^{3}$

2

$1.641 \mathrm{Mg} / \mathrm{m}^{3}$

$0.985 \mathrm{~mm}^{-1}$

660

$0.37 \times 0.25 \times 0.18 \mathrm{~mm}^{3}$

2.95 to $34.55^{\circ}$.

$-16<=\mathrm{h}<=15,-12<=\mathrm{k}<=11,-23<=\mathrm{k}<=23$

16842

$5188[R($ int $)=0.0263]$

$99.7 \%$

Analytical

0.890 and 0.809

Full-matrix least-squares on $F^{2}$

5188 / 0 / 186

1.062

$R 1=0.0323, w R 2=0.0827$

$R 1=0.0380, w R 2=0.0870$

0.538 and -0.346 e. $\AA^{-3}$ 
Table S2. Hydrogen bonds for mojvj9 [^̊ and ${ }^{\circ}$ ].

\begin{tabular}{llllr}
\hline $\mathrm{D}-\mathrm{H} \ldots \mathrm{A}$ & $\mathrm{d}(\mathrm{D}-\mathrm{H})$ & $\mathrm{d}(\mathrm{H} \ldots \mathrm{A})$ & $\mathrm{d}(\mathrm{D} \ldots \mathrm{A})$ & $<(\mathrm{DHA})$ \\
\hline $\mathrm{O}(21)-\mathrm{H}(21) \ldots \mathrm{O}(1)^{\mathrm{a}}$ & $0.78(2)$ & $2.03(2)$ & $2.7184(12)$ & $147(2)$ \\
$\mathrm{O}(21)-\mathrm{H}(21) \ldots \mathrm{O}(61)^{\mathrm{a}}$ & $0.78(2)$ & $2.22(2)$ & $2.8438(13)$ & $137(2)$ \\
\hline
\end{tabular}

Symmetry transformations used to generate equivalent atoms:

a $1-x, 1-y, 1-z$

\section{References}

1 G. M. Sheldrick, Acta Cryst. A, 2008, 64, 112-122. 